\title{
Parte III
}

\section{VALORACIÓN FEMENINA Y EL SENTIDO DE IDENTIDAD ETNICA DE QASIRI}

\author{
Cortez Farfán Leonardo \\ Delgado Chávez. Nathaly \\ Delgado López Natali \\ Lazo Meneghini Ivanna \\ Quisapicondor Salazar Milagros \\ Vela Soto Giovanna
}

\section{Pueblo de Qasire y su significado}

Qasiri, deriva del quechua Qasiriy que significa abstenerse, tranquilizarse, calmarse, es decir abstente, tranquilízate, cálmate. Pertenece al distrito de Pauza en Ayacucho, a 3000 msnm, dicho distrito está formado por 7 anexos: Qasire, Huancara, Marán, Mirmaca, Pirca, Rauripa, Toncio y 8 barrios: Acola, Atapillo, Ayraranca, Huampo, Hanan Huayllas, Huánuco, Otococha, Urin Huayllas.

La comunidad Qasiri fue conocida por mucho tiempo como "pueblo de mujeres" o warmillaqta. Las razones de ello tienen explicaciones diversas, basadas en la religiosidad, historia y la costumbre.

\section{Qasiri: un pueblo de mujeres}

Dentro de las razones de esta identidad femenina, se encuentran una primera de carácter religioso y tiene que ver con la presencia del Apu Sara Sara; la segunda está relacionada a la salud del pueblo; y las dos últimas con migraciones.

Cuentan que otrora, en Qasiri habían mujeres solteras y hermosas, que cantaban y bailaban con mucha gracia por que la Virgen de las Nieves las enseñó a bailar la Huaylía, y esta actividad es heredada de generación en generación, aunque también se puede aprender por afición. Se dice que al paso de los forasteros llegaban para adorar a la Virgen de las Nieves y se juntaban con estas mujeres; pero el Apu protector de la zona, el volcán Sara-Sara (de sexo femenino) se puso celosa.

Por eso que, entre una lluvia de piedras que mandó tiempo atrás, le encargó a una la función de no dejar que los hombres se queden. Si es que una mujer se cansaba de su marido o este le era infiel, daba tres vueltas alrededor de la piedra y el hombre moría hinchado y botando sangre. Incluso se decía que los niños no pasaban de los tres años, pues morían. La mujer era sacralizada, al igual que en muchos otros grupos humanos. Este caso puede ser explicado por la relación mujer-fecundidad, que María Rostworowski, explica de la siguiente manera: "Las deidades femeninas estaban 
asociadas a la obtención de alimentos y las actividades que los producían, es decir, la agricultura y la pesca. Además el elemento femenino divino representaba a la madre fecunda. Así se entiende por qué ciertas divinidades eran tratadas como "madres": la tierra (Pachamama), el mar (Mama Cocha), la luna (Mama Quilla); el maíz (Mama Sara), la papa (Mama Acxo), la coca (Mama Coca)". 5

En relación a las razones de salud, se dice que antiguamente era común la presencia de cuadros de viruela que generaban muchas muertes, mayormente entre los hombres. Asimismo, se explica que debido a las sequías prolongadas que se vivían en la zona y en Qasiri en particular, traía como consecuencia que el hombre salga a las comunidades aledañas a conseguir alimentos para su subsistencia, dejando a las mujeres al cuidado de todo. Otra explicación es que en los viajes tanto de comercio e intercambio, los hombres consumían mucho alcohol, situación que generaba permanecer mucho tiempo fuera del pueblo. Como no había médicos ni la medicina como lo es actualmente, la mayoría moría con neumonía o bronconeumonía. Otra enfermedad recurrente era aquellas relacionadas con la próstata". ${ }^{6}$

Finalmente, se explica que Qasiri, al estar ubicada en la zona sur de Ayacucho, limita con la provincia de La Unión, Arequipa. Esa zona fue lugar de paso obligado para transportar el cañazo procedente de Majes en la década de 1950, y los qasirinos trabajaban de peones de los arrieros y demoraban en trasladar la mercancía, aproximadamente dos semanas. Además con las comunidades de Cotahuasi y Caravelí también aledañas - intercambiaban productos como la papa y el maíz por el arroz. Y los transeúntes al pasar por Qasiri no veían hombres y por eso lo denominaron como el pueblo de mujeres.

Aunque, don Julio nos dice que: "los gamonales o hacendados de Pausa, abusando de su autoridad, les quitaban sus chacras y territorios a los comuneros de Qasiri, por eso tenían que migrar hacia otros pueblos aledaños como Arequipa, Chala, Ocoña, etc. en busca de alimentos. Como el camino era tan largo, morían de pena y cansancio, muchos hombres trabajaban sembrando arroz y regresaban con cuatro sacos o quintales de arroz que les duraban para todo el año, pero el trabajo les demandaba mucho tiempo, por eso regresaban a Qasiri una vez al año, débiles y enfermos, siendo además mellados por el frío o el alcohol. Incluso, para que los niños puedan sobrevivir los dejaban en los pueblos aledaños, para que trabajen por sacos de arroz y quintales de maíz (como una forma de pago), algunos regresaban luego de trabajar en las chacras aledañas, pero otros se quedaban, crecían y formaban sus familias en la zona de trabajo"?.

5 ROSTWOROWSKI, María. Enciclopedia Temática del Perú-Incas (Tomo I). Lima, Empresa Editora El Comercio S.A., 2004. Pág. 133.

6 Alsemio Espinoza del Valle, hijo de migrantes del pueblo de Ocoña, aledaño al pueblo de Qasiri. Reside en Quebrada del Paraíso.

Julio Huamani Córdova reside en Jardines del Paraíso, segunda etapa, es hijo de migrantes del pueblo de Qasire: José Huaranca Castro y Sara Garayar V. 


\section{Explicaciones sobre la alta valoración femenina de las mujeres qasirinas}

Ante la ausencia de hombres — cualquiera sea el motivo_-, la mujer predominaba y tomaba las decisiones de la comunidad. En las entrevistas realizadas en Qasiri por Marianne Eyde (1980) para la elaboración de su tesis, encontró que las mujeres ocupaban cargos públicos muy importantes como la Alcaldía y Gobernación e incluso la Mayordomía, las mismas que eran despedidas al final de su gestión, con el canto de las mujeres del pueblo: las Huaylías.

Las mujeres también cumplían un rol importante en la producción agrícola, particularmente en el riego de la tierra. Sean solteras o viudas eran las encargadas de dicha actividad, aunque también se reconocen la participación de los hombres a través de jornadas de contrapunteo o competencia complementaria y siempre las mujeres las superaban. Se dice por ello que las mujeres son muy trabajadoras y de carácter fuerte.

\section{La realidad de hoy en Qasiri}

El pueblo de Qasiri ha sufrido cambios a través del tiempo. Hace tres años, sufrió un fuerte sismo, un terremoto que ocasionó que las viviendas de piedra se derrumben, siendo reconstruidas de adobe posteriormente. Cuando no es tiempo de fiesta, solo 20 personas la habitan, entre 10 o 12 familias tal vez. Hace 50 años era un lugar céntrico, debido a la presencia de su Iglesia para la virgen de Qasiri, la última antes del límite de Ayacucho con Arequipa. Según mitos narran que ella se encontraba sentada en una piedra grande y no quería moverse, por ello construyeron su iglesia en el mismo lugar donde la encontraron.

Actualmente, el trabajo de la tierra queda abandonado y el pueblo se aproxima a una desaparición inminente, que, de no ser por la fiesta de la Virgen de las Nieves, ya se habría dado hace mucho tiempo. Mantienen un gran lazo de amistad con los anexos arriba mencionados y mantienen su identidad. Comparten costumbres en común, como es el caso de las festividades religiosas con los otros pueblos vecinos por lo cual siempre se da un profundo respeto y cooperación entre ellos.

Las mujeres, al igual que la mayoría de jóvenes, migran a Lima para estudiar carreras técnicas y universitarias (hay contadoras, arquitectas, ingenieras) o para trabajar como empleadas del hogar, en el comercio, entre otros.Los qasirinos de hoy reconocen la función importante de las mujeres frente a la ausencia de hombres, por lo que se vieron obligadas a hacerse cargo de las chacras y a trabajar en todo lo que hiciera falta. Manifiestan que ellas estuvieron muy vinculadas a la actividad económica y consideran que no hay diferencia entre el trabajo del hombre y el de la mujer, por ello su carácter fuerte. Asimismo, las consideran trabajadoras y que usaban el pico y la lampa igual que los hombres, con la misma fortaleza inquebrantable o algo más. Por otro lado, las mujeres dicen que así tenía que ser, si no hay hombres, ellas mismas tienen que hacer todo y no lo consideran un problema. 
Los migrantes qasirinos en Lima, con su aporte y esfuerzo propio y motivado por las limitaciones para regresar a Qasiri, fundaron en 1976 la Asociación Progresista Hijos de Casire en el distrito de Villa El Salvador. Y es el principal centro del encuentro familiar, de amistad y reproducción de tradiciones y costumbres que les permite preservar la identidad. La composición en la asociación es equilibrada, ya que en la participación influyen factores económicos y de tiempo; además, tienen un Comité de Damas, brazo de derecho de la Junta Directiva.

Actualmente se celebra y rinde homenaje a la Virgen de las Nieves, en su fiesta central que es el tercer domingo de agosto. Este año la mayordomía estuvo a cargo de 3 hermanas del pueblo y que viven hace muchos años en Lima. La Huaylía está a cargo de mujeres voluntarias, que por herencia y tradición son ejercidas con mucho fervor. También es resaltante la participación de la sargentana que recayó en una niña, dicen que solo las solteras y niñas pueden ocupar este cargo, pues se entregan puras a la virgen, y son las que cuidan y marchan delante de la virgen durante su procesión. El vestuario que utilizan, es simple, solo llevan una franja encima de su ropa en el cual esta grabado su nombre, además tiene colgado en su ropa unos billetes, según dicen es la donación de sus familiares. La ceremonia consiste en una mezcla de religiosidad católica y andina, acompañada de danzantes y mujeres invitadas de otro pueblo, con sus cantos se unen a la ceremonia.

\section{El sentido de la celebración de la Virgen de las Nieves}

La Virgen de las Nieves de QasirI, la Mamacha de las Nieves, es muy venerada por todos los qasirinos, quienes piden todo tipo de favores y bendiciones, principalmente por salud y trabajo. No falta quien la pida encontrar una persona buena con quien casarse y de preferencia sea qasirino, como lo atestigua el señor Quispe, quien nos cuenta que le pidió a la Virgen de las Nieves que le concediera una buena mujer para su hijo, y así fue, al poco tiempo su hijo conocería a una chica que cantaba en una de las huaylías, una qasirina, que pronto le robó el corazón. Este es uno de los tantos favores que le concedió al señor Quispe.

Al preguntarle, desde cuando es devoto, nos cuenta que desde hace muchos años, cuando llegó a Lima, no tenía dinero y con la justa podía mantener a su familia; pero eso no era impedimento para querer participar de la celebración del día de la Virgen de la Nieves, él quería agasajarla llevando un conjunto de bailarines.

Era el mes de junio y le dice a su esposa: "mira ya se acerca agosto y quisiera traer unos bailarines para la Virgen", esta se niega alegando que tenían muchas carencias ya que su casa era de esteras en Villa María del Triunfo y los juntaban para construir su casita. Al poco tiempo su mujer se enfermó, había huelga de médicos y ella tuvo que pasar un mes en cama. Aún no se había restablecido cuando le dice a su esposo: "creo que la virgen me está castigando, mejor le mandamos a los bailarines con arpa y violín”, y así fue, ese año recibieron muchos favores; así, a partir de ese momento, año a año, participan de las celebraciones. También fueron ocupando diversos cargos directivos dentro de la asociación y como resultado: sus hijos se 
hicieron profesionales y ahora logró construir su casa de tres pisos. Así, le agradecen a la virgen que les ha dado trabajo, salud y todo lo que le piden, los tienen mucha fe. Todos los años en el mes de agosto se celebra el día de la Virgen de las Nieves de Qasiri y para la realización de estas celebraciones uno puede contratar bailarines, músicos, huaylías o mandar a oficiar una misa a cambio de algún favor solicitado a la Virgen: Pues es considerada muy milagrosa y virtuosa, en la memoria y realizaciones de los lugareños e hijos. 